\title{
Temporal changes in plankton of the North Sea: community shifts and environmental drivers
}

\author{
Santiago Alvarez-Fernandez*, Han Lindeboom, Erik Meesters \\ Institute for Marine Resources \& Ecosystem Studies (IMARES), Wageningen University \& Research Centre, PO Box 167, \\ 1797SZ ‘t Horntje, The Netherlands
}

\begin{abstract}
This paper analyses long-term and seasonal changes in the North Sea plankton community during the period 1970 to 2008. Based on Continuous Plankton Recorder (CPR) data covering $38 \mathrm{yr}$, major changes in both phytoplankton and zooplankton abundance and community structure were identified. Regime changes were detected around 1978, 1989 and 1998. The first 2 changes have been discussed in the literature and are defined as a cold episodic event (1978) and a regime shift towards a warm dynamic regime (1989). The effect of these 2 regime changes on plankton indicators was assessed and checked against previous studies. The 1998 change represents a shift in the abundance and seasonal patterns of dinoflagellates and the dominant zooplankton group, the neritic copepods. Furthermore, environmental factors such as air temperature, wind speed and the North Atlantic water inflow were identified as potential drivers of change in seasonal patterns, and the most-likely environmental causes for detected changes were assessed. We suggest that a change in the balance of dissolved nutrients driven by these environmental factors was the cause of the latest change in plankton community structure, which in turn could have affected the North Sea fish community.
\end{abstract}

KEY WORDS: Seasonal patterns · Regime shift · North Sea · Dinoflagellates · Zooplankton • Nutrients

\section{INTRODUCTION}

\section{North Sea plankton changes}

The North Sea planktonic system has been thoroughly studied during the past 6 decades (Colebrook 1979, Edwards et al. 2001, Reid et al. 2003, Beaugrand 2004b). Continuous Plankton Recorder (CPR) data provided insight into the long-term trends and seasonal patterns of both phyto- and zooplankton and their relationships with hydrographical factors as well as climatological events.

A cold episodic event in the North Sea in the late 1970s has been described and widely acknowledged (Reid et al. 2000, Reid \& Edwards 2001, Edwards et al. 2002, Beaugrand 2004a, Beaugrand \& Ibanez
2004, Weijerman et al. 2005). These cold years were characterised by low sea surface temperature (SST) values in the North Sea (Becker \& Pauly 1996), which were particularly harsh in the shallower southern North Sea. Becker \& Pauly (1996) related these lowSST years post-1977 to air-sea exchange processes, which in turn depended on the North Atlantic atmospheric circulation.

Edwards et al. (2002) described how during this period (1) the phytoplankton bloom was smaller than average and occurred later in the year, (2) many early spring diatom species were absent from the spring bloom, and (3) Chaetoceros spp., one of the most abundant diatoms in the North Sea, were only present in small numbers. Edwards et al. (2002) also described the crash of the Ceratium macroceros pop- 
ulation, a very abundant dinoflagellate which may have lost its niche as a result of the late development of the spring bloom.

A second overall change in North Sea plankton occurred during the 1980s (Reid et al. 2001a, Beaugrand \& Ibanez 2004, Alheit et al. 2005, Weijerman et al. 2005, McQuatters-Gollop et al. 2007). During this period there was a strong biogeographic shift of warm-water copepod species (associated with a decrease in cold-water species), as well as of warmwater fish species, in the northeast Atlantic (Beaugrand \& Reid 2003). This indicated a change in the pelagic ecosystem of the northeast Atlantic towards a warmer dynamic regime, which seems to have been driven by climatic variables.

In contrast with the late 1970s cold episodic event, the North Sea entered a warm-biological dynamic regime after the North Sea warm episodic event from 1988 to 1992 (Edwards et al. 2002). This regime can be characterised by (1) higher Phytoplankton Colour Index (PCI) values in the central North Sea, particularly during winter and summer; (2) an extended phytoplankton season; and (3) a change in the zooplankton community structure (Reid et al. 2001a). All these changes have been related to different environmental factors, such as the increase in SST and changing Atlantic water inflow through the northern North Sea (Reid et al. 2003).

SST increase has also been related to changes in the meroplankton of the North Sea, particularly Echinocardium cordatum, decapod crustaceans, and bivalve larvae (Kirby et al. 2007, 2008). These changes in turn affect benthic-pelagic coupling in the North Sea, restructuring the trophic interactions (Kirby \& Beaugrand 2009). Beaugrand et al. (2003) showed how fluctuations in plankton have resulted in long-term changes in cod recruitment in the North Sea, demonstrating the propagation of changes through different trophic levels. A link has also been made to changes in the North Sea horse mackerel fishery (Reid et al. 2001a).

\section{Regime shift considerations}

The transitions between the above-mentioned periods have been described in the literature as regime shifts. The term regime shift has been applied to apparent shifts in oceanic and climatic conditions and marine community structure around the world. Collie et al. (2004) defined regime shifts as low-frequency, high-amplitude changes in oceanic conditions that may be specifically pronounced in biologi- cal variables and propagate through several trophic levels.

Although all these transitions have been considered regime shifts in the past, not all long-term changes in time series should be considered regime shifts. A change could be contained and be exclusive to one part of a system, not transferred through different trophic levels, or not consistent over time.

The North Pacific (Hare \& Mantua 2000) and the North Sea (Reid et al. 2001a, Weijerman et al. 2005) showed 2 regime shifts around 1977-79 and 1988-89, but the late 1980s shift did not return the system to the previous state. Weijerman et al. (2005) pointed out the possibility of another shift in the late 1990s, hinted at by their results. This late 1990s shift coincided with the second of the 2 pulses of oceanic incursion into the North Sea from the north around 1988 and 1998 that co-occurred with strong northward advection of anomalously warm water at the edge of the eastern British continental shelf (Reid et al. 2001b). Several studies relating to different trophic levels support the idea of a shift in the late 1990s, ranging from herring recruitment failure (Payne et al. 2009) to seabird breeding failure along the North Sea coast (Proffitt 2004, Wanless et al. 2005). Although there seemed to be a connection to changes in plankton dynamics after 1998, no indepth study of the plankton system before and after this year has been carried out to our knowledge.

In the present study, a selection of plankton indicators taken from CPR survey data covering 1970 to 2008 were examined to investigate long-term changes in the planktonic system of the central North Sea, southern North Sea and English Channel. These indicators were ordinated by principal component analysis (PCA), and the resulting principal components (PCs) were tested for long-term and step changes using different techniques. Detected changes were assessed in relation to a range of local and global environmental variables, and the possibility for propagation to higher trophic levels.

\section{MATERIALS AND METHODS}

\section{Study area}

All data were aggregated into 3 different regions: central North Sea $\left(55-58^{\circ} \mathrm{N}\right)$, southern North Sea $\left(51-55^{\circ} \mathrm{N}\right)$, and the English Channel (Fig. 1).

These regions vary in bathymetry and hydrodynamic properties; e.g. the central North Sea is deeper than the southern part. This affects the mixing of the 


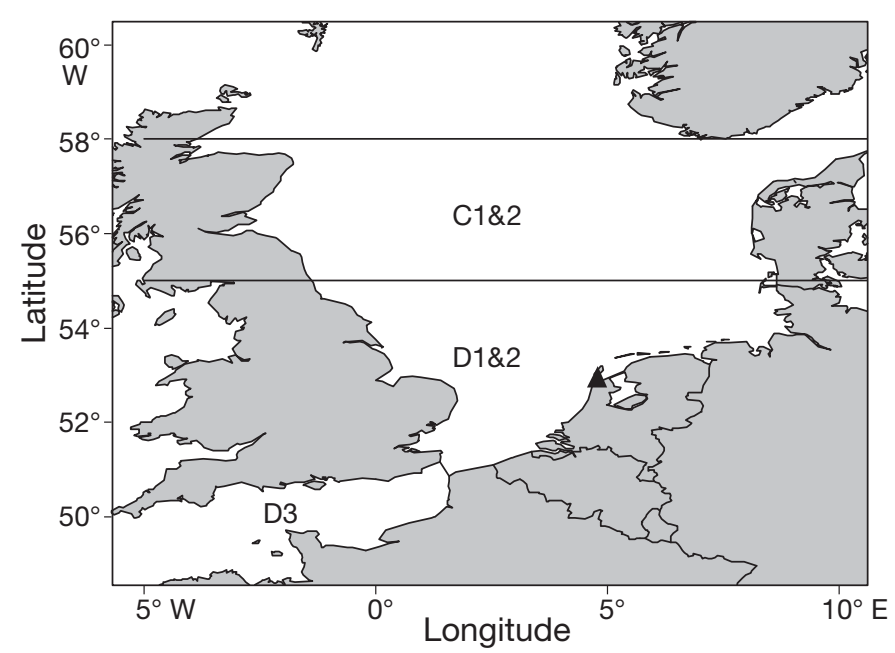

Fig. 1. Study areas and their correspondence with Sir Alister Hardy Foundation for Ocean Science standard areas. The Royal Netherlands Meteorological Institute (KNMI) climatological station De Kooy is indicated $(\boldsymbol{\Delta})$

water, causing the central part to be stratified at times during warmer periods of the year (Richardson \& Pedersen 1998).

\section{Data collection}

\section{Plankton time series}

CPR data were obtained from the Sir Alister Hardy Foundation for Ocean Science (SAHFOS). Plankton data were retrieved as monthly mean counts per sample per area from standard areas C1, C2, D1, D2 and D3 covering the North Sea region (Fig. 1). Each sample represents 10 nautical miles of tow and approximately $3 \mathrm{~m}^{3}$ of filtered water (Warner \& Hays 1994). The variables included in the analyses were:

PCI. PCI is a semi-quantitative estimation of algal biomass. It is based on a relative scale of greenness and is determined by reference to a standard colour chart (McQuatters-Gollop et al. 2007). Other studies have proven the validity of PCI as a representation of phytoplankton biomass (Batten et al. 2003, Raitsos et al. 2005).

Total copepods. This variable was log-transformed $\left(\log _{10}(\right.$ Abundance +1$\left.)\right)$ in order to homogenise the variance.

Dinoflagellates and diatoms. Because PCI does not give information about the phytoplankton community structure, data on total numbers of diatoms and dinoflagellates were also gathered for an in-depth analysis. Consequently, 6 new variables were added. Potential redundancy between variables was also assessed (see Table S1 in Supplement 1, and Supplement 2 at www.int-res.com/articles/suppl/m462p021 _supp.pdf).

Copepod assemblages. Beaugrand (Beaugrand et al. 2002, Beaugrand 2004a) proposed different assemblages of plankton species to be used as indicators of changes in the ecosystem (Table 1). Abundances per area per month of 26 representative copepod species were retrieved from SAHFOS and aggregated according to their ecological preference. Once the abundance data were aggregated into the 3 regions, the ratio of warm-water species (assemblages A1 and A2), and cold-water species (assem-

Table 1. Zooplankton species-assemblage indicators and their ecological preferences (after Beaugrand $2004 \mathrm{a}$ ). A1 and A2 are considered warm-water copepod species; A5, A6 and A7 are considered cold-water copepod species

\begin{tabular}{|c|c|c|c|}
\hline $\begin{array}{l}\text { Species } \\
\text { assemblage }\end{array}$ & $\begin{array}{l}\text { Species assemblage } \\
\text { indicator }\end{array}$ & Species composition & Ecological preference \\
\hline A1 & $\begin{array}{l}\text { Warm-temperate } \\
\text { pseudo-oceanic species }\end{array}$ & $\begin{array}{l}\text { Euchaeta gracilis, Euchaeta hebes, } \\
\text { Ctenocalanus vanus, Calanoides carinatus }\end{array}$ & $\begin{array}{l}\text { Warm water along the } \\
\text { European shelf }\end{array}$ \\
\hline A2 & $\begin{array}{l}\text { Temperate } \\
\text { pseudo-oceanic species }\end{array}$ & $\begin{array}{l}\text { Rhincalanus nasutus, Eucalanus crassus, } \\
\text { Centropages typicus, Candacia armata, } \\
\text { Calanus helgolandicus }\end{array}$ & Oceanic and neritic waters \\
\hline A3 & Coastal species & $\begin{array}{l}\text { Isias clavipes, Anomalocera patersoni, } \\
\text { Labidocera wollastoni }\end{array}$ & Shallow and coastal habitat \\
\hline A4 & Shelf-sea species & $\begin{array}{l}\text { Centropages hamatus, Temora longicornis, Pseudo- } \\
\text { calanus spp. (including adult), Paracalanus spp. }\end{array}$ & Neritic distribution \\
\hline A5 & Cold-temperate species & $\begin{array}{l}\text { Aetidus armatus, Pleuromamma robusta, } \\
\text { Acartia spp., Metridia lucens }\end{array}$ & $\begin{array}{l}\text { Mixed water usually found } \\
\text { at the boundary between } \\
\text { warm and subarctic water }\end{array}$ \\
\hline A6 & Subarctic species & $\begin{array}{l}\text { Heterorhabdus norvegicus, Scolecithricella spp., } \\
\text { Euchaeta norvegica, Calanus finmarchicus }\end{array}$ & Subarctic water \\
\hline A7 & Arctic species & $\begin{array}{l}\text { Calanus hyperboreus, Metridia longa, } \\
\text { Calanus glacialis }\end{array}$ & Arctic water \\
\hline
\end{tabular}


blages A5, A6 and A7) to total copepods per region was calculated. These warm- and cold-water copepod species ratios serve as a representation of the copepod community structure and also give information about the other copepod assemblages, i.e. the warm-water copepods:total copepods ratio could change without changes in the original warm-water copepod abundances, but due to changes in shelf-sea species (assemblage A4). Subsequent analyses used these newly generated time series.

\section{Environmental time series}

Oceanographic variables. Monthly SST and sea surface salinity (SSS) data covering the study area were obtained from the International Council for the Exploration of the Sea (ICES). CPR coverage is scarce in coastal areas, so the plankton data set represents mainly open-sea plankton. Because of the gradient from coastal to open sea in both SST and SSS, inclusion of coastal measurements would alter the average values significantly. For this reason, coastal measurements (up to $20 \mathrm{~km}$ from the coast) were removed to avoid the influence of riverine inputs in both temperature and salinity. Subsequently, monthly averages per region were calculated.

Monthly data on Atlantic water inflow to the North Sea was obtained from a numerical ocean model, NORWECOM, and it was represented as flow in and out of the North Sea through a section from Norway to the Orkneys along $59.17^{\circ} \mathrm{N}$ (Reid et al. 2003). Because we were interested in differences in North Sea regions, water flow was also obtained, from the same model, through a second section along $55^{\circ} \mathrm{N}$ from the UK to Germany. Water flow was represented by southward and northward transport (water moving south and north, respectively) and the difference between them as net transport.

Atmospheric variables. Monthly wind speed and direction, air temperature, sea-level pressure and humidity data series from De Kooy climatological station $\left(52.92^{\circ} \mathrm{N}, 4.78^{\circ} \mathrm{E}\right)$ were gathered from the Royal Netherlands Meteorological Institute (KNMI) for the period 1970 to 2008. This station was selected because of its time coverage, and it has been previously used in similar analyses (Weijerman et al. 2005).

Two more climate-related variables were included. The first, the Hurrell North Atlantic Oscillation (NAO) winter index (NAOi), a December-March index of the NAO (Hurrell \& Deser 2009) based on the difference in normalised sea-level pressure (SLP) between Lisbon, Portugal and Stykkishólmur/Rey- kjavik, Iceland, was obtained from www.cgd.ucar. edu/cas/jhurrell/indices.html. The second, northern hemisphere surface temperature anomaly (NHTa) data, was obtained from the Hadley Centre for Climate Prediction and Research (www.metoffice.gov. uk/hadobs). These data are used as an index of temperature changes. The data set is based on regular measurements throughout the northern hemisphere of air temperature at a global network of long-term land stations and on SST measured from ships and buoys, and consists of annual differences from the 1951-80 monthly averages (Brohan et al. 2006).

Water nutrients. Total soluble nitrogen, total soluble phosphorus and silica data series were obtained from ICES. Data were calculated as $\mu \mathrm{mol} \mathrm{l}^{-1}$ monthly averages, representing surface concentrations (as collected by water bottle sampling <10 m depth), and covered a time span of 20 yr from 1988. As with SST and SSS, nearshore measurements were removed to avoid the influence of coastal nutrient dynamics, more related to riverine inputs. When available, data on different nitrogen compounds (i.e. $\mathrm{NO}_{3}, \mathrm{NO}_{2}$, $\mathrm{NH}_{4}$ ) were also obtained from the same database, time period and depth.

\section{Analyses \\ Principal component analysis}

As a first step, 2 PCAs were run. Both PCAs used data covering $38 \mathrm{yr}$ and, as monthly values were used, a total of 456 time steps (38 yr $\times 12 \mathrm{mo} \mathrm{yr}^{-1}$ ) were analysed $\mathbf{1}$. The first PCA ordinated 12 plankton variables (PCA1, total copepod abundance, warmand cold-water copepod ratios; $456 \times 12$ matrix) based on correlations (Legendre \& Legendre 1998, Oksanen et al. 2010); the second PCA included in addition diatom and dinoflagellate abundances, giving a total of 18 plankton variables $(456 \times 18$ matrix $)$ based on correlations. These 2 PCAs were compared to identify the best representation of the system (see Figs. S1 \& S2 and Table S2 in Supplement 2 at www. int-res.com/articles/suppl/m462p021_supp.pdf). The resulting PCs were used as indicators of the plankton ecosystem state, and the following analyses were carried out.

\footnotetext{
${ }_{1}^{1}$ Low statistical power in regime-shift detection for ecological time series is caused by their inherent short length (Andersen et al. 2009), but the use of monthly values instead of yearly averages should overcome this issue
} 


\section{Regime detection analyses}

Split-moving window boundary analysis (SMW). SMW (Beaugrand 2003) was used to detect regime changes in each of the PCs. For this analysis, each PC axis was converted from a linear vector into a $12 \times 38$ matrix ( 1 row mo ${ }^{-1}$ and 1 column $\mathrm{yr}^{-1}$ ).

The calculation of SMW is realised in 4 steps: (1) A window of even-numbered size is introduced at the beginning of the time series matrix. (2) This window is then divided into 2 half-windows containing the data of all months for the same amount of years. (3) An association coefficient (Euclidean distance in this case) is used to evaluate the differences between the time periods contained in these 2 windows. A multiple response permutation procedure (Mielke et al. 1981) is applied to test the 2 periods on the basis of the information provided by all months. (4) The window is then moved from year to year, repeating steps 2 and 3 until the end of the time series is reached. This procedure provides a $\mathrm{p}$-value for each year representing the statistical significance of a year being the limit between 2 different regimes.

Change point detection (CPD). A CPD method (Zeileis et al. 2003) as described by Quandt (1958) was applied as a hypothesis-testing method. To avoid the problem of inflation of $\mathrm{p}$-values due to multiple testing, the supremum of $F$ in the $F$-distribution $(\sup (F))$ was used as proposed by Andersen et al. (2009). The $\mathrm{R}$ package 'strucchange' was used for this analysis (Zeileis et al. 2003).

Hierarchical clustering. Constrained hierarchical clustering was applied to the $38 \times 12$ matrix of each PC (Gordon \& Birks 1972). In combination with the previous techniques, this allows us not only to see which years were more similar but also to detect sudden changes in the time series. The R package 'rioja' was used for this analysis (Juggins 2009).

\section{Environmental drivers}

In order to assess potential environmental drivers of the system, the correlation between environmental variables and the PCs was investigated, including lag periods of up to 3 mo. These correlations were investigated both with the original PCs and time series, and with detrended PCs and time series. Detrending was carried out by means of a general additive model (GAM) (Wood 2006), with 'Month' (1 to 12) as a smoothing function. The residuals of these models were considered the new detrended data series.
Variables showing a Pearson correlation value with a PC greater than 0.5 were pre-selected as possible explanatory variables in a GAM. In order to prevent problems caused by the presence of outliers and collinearity, these variables were subjected to a data exploration and selection process as suggested by Zuur et al. (2010).

The variables that passed these data exploration protocols were included as smoothing functions in a generalised additive mixed model (GAMM) (Wood 2006), and a model selection process was performed using the Akaike information criterion (AIC) as a means of comparing the fit of different models.

Serial autocorrelation was accounted for by minimising autocorrelation in the model residuals. This was achieved by fitting an autoregressive-moving average correlation structure (ARMA) in a GAMM (Wood 2006, Pinheiro et al. 2009), using again the AIC to select the best model (Zuur et al. 2009).

In a parallel analysis, the yearly variables (i.e. NAOi and NHTa) were tested for regime changes via the CPD method. This analysis was run independently, as the frequency of the variables did not match the rest of variables considered.

All analyses were performed using the $\mathrm{R}$ free statistical software environment ( $R$ Development Core Team 2012)

\section{RESULTS}

A representation of the central North Sea data included in the PCA can be seen in Fig. 2. Temporal patterns previously described in the North Sea are visible. PCI was considerably higher after 1988 (Fig. 2a), which represented higher phytoplankton biomass. The practical disappearance of warm-water copepods (Fig. 2f) together with the increase in coldwater copepods (Fig. 2e) immediately post-1977 is in agreement with previous findings related to the late 1970s North Sea cold episodic event. The opposite situation post-1988, i.e. increase in warm-water copepods and decrease in cold-water copepods, was an indication of the warm regime in the North Sea since the late 1980s.

\section{Principal component analysis}

Plankton data were ordinated by 2 PCAs to create an index of the plankton ecosystem state through time. The output of both PCAs, one ex- 


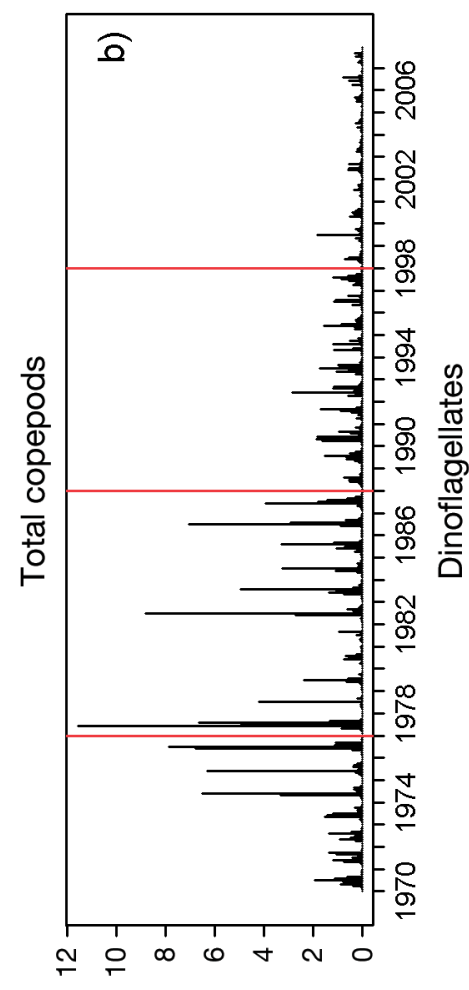

Counts

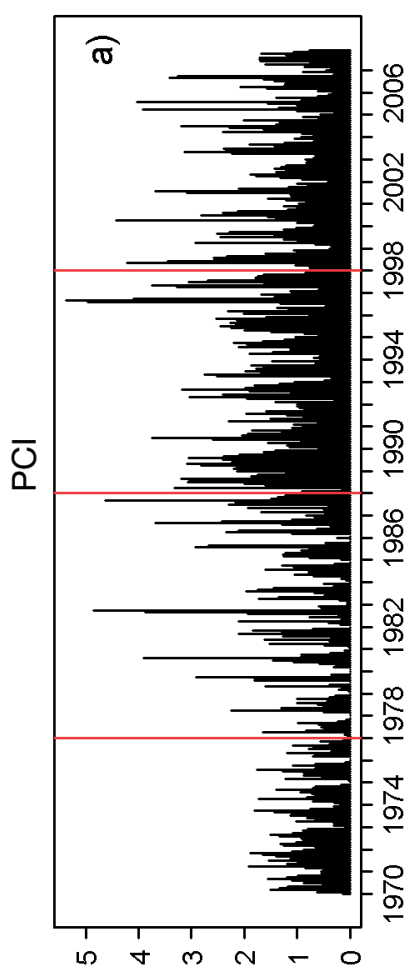

Colour index

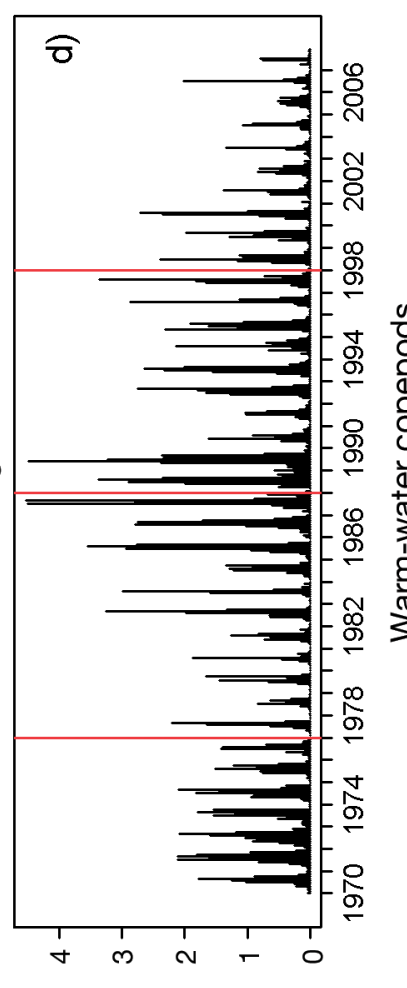

Counts $\left(\times 10^{5}\right)$

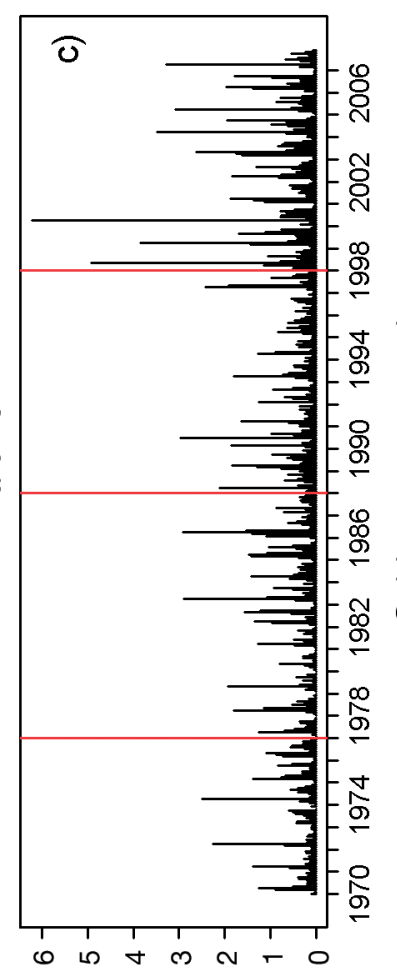

Counts $\left(\times 10^{5}\right)$

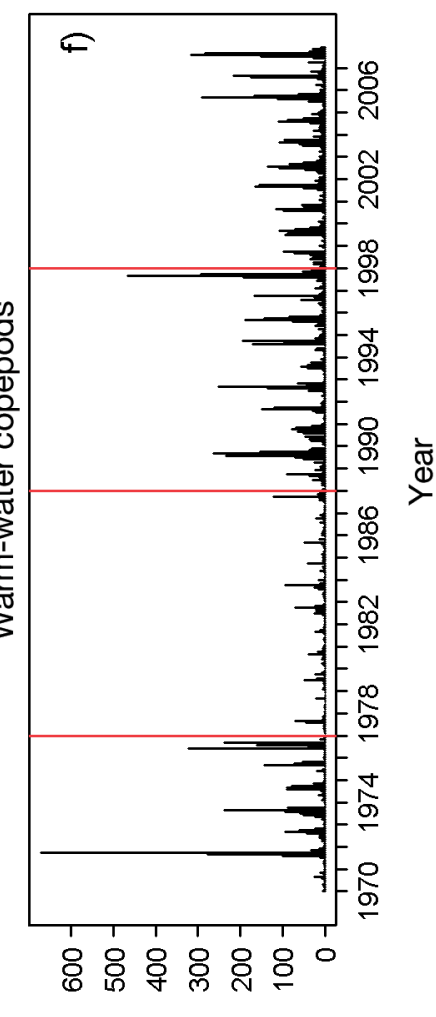

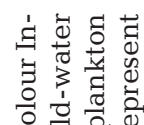

U 용

원 $N$

牙它

용

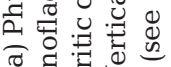

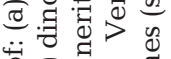

范

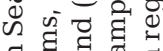

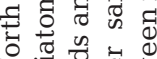

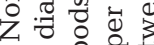

তี

屯․ำ

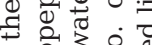

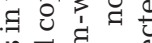

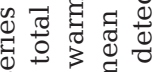

w

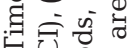

교융

我希造造

Counts

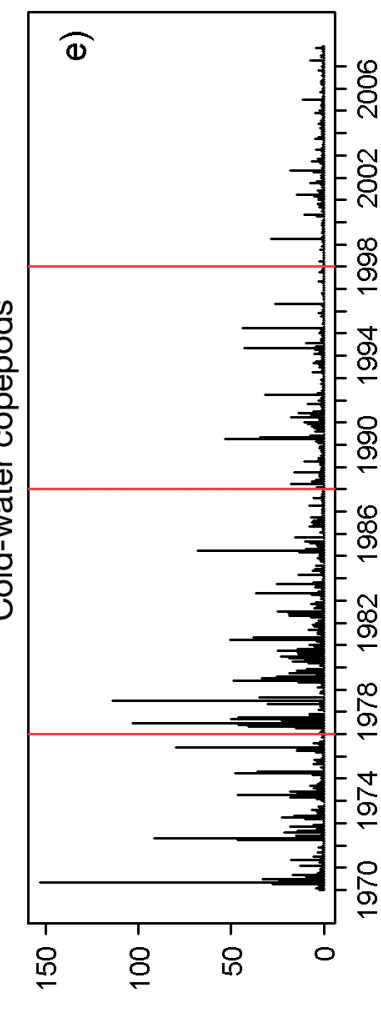

Counts

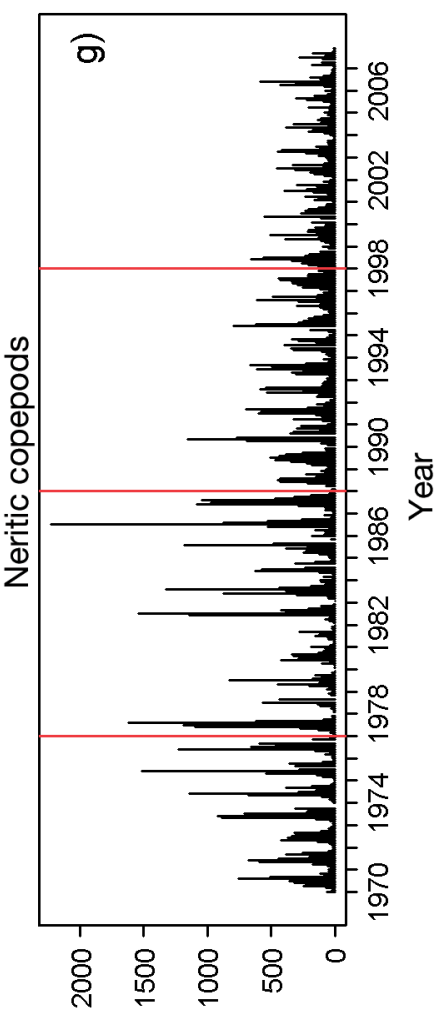

Counts 
cluding diatom and dinoflagellate abundance data and the other including them, was compared and PCs were selected by 1 of 2 criteria: (1) PCs that accumulate to at least $70 \%$ of the variation in the original data, (2) detection of a change point in a scree-plot of the eigenvalues, marking a separation between PCs with a large explanatory value and those with less explanatory value. This change point is commonly referred to as the 'elbow effect' (Zuur et al. 2007). The number of PCs selected for further analyses was defined by the first of these criteria reached.

For the first PCA, the elbow effect appeared after the second $\mathrm{PC}$, while for the second PCA, where diatoms and dinoflagellates were included, it appeared after the third PC (Fig. S1 in Supplement 2). Hereinafter, all results and discussion will be addressing the second PCA, including diatom and dinoflagellate abundance data. A comparison of both PCAs can be found in Supplement 2.

Interestingly, the loadings for each variable in each of the studied PCs showed differences between groups, but are roughly consistent within each group, which indicated that no regional differences needed to be considered (Table 2).
The first $\mathrm{PC}\left(\mathrm{PC}_{1} ; 28.8 \%\right.$ explained variance; Fig. 3a, Table 2) represents the seasonal patterns of total abundance of phytoplankton (PCI) and zooplankton (total number of copepods). It was also related to phytoplankton community composition (diatom and dinoflagellate abundances).

The second PC (PC2; $12.7 \%$ explained variance; Fig. 3b, Table 2) represents a temporal pattern, in-

Table 2. Loadings of the different variables for the first 3 principal components (PC) of the second principal component analysis including all biological variables. Explained variation was 28.8, 12.7 and $10.5 \%$ for PC axes 1, 2 and 3 respectively. PCI: Phytoplankton Colour Index

\begin{tabular}{|lrrr|}
\hline & PC1 & PC2 & PC3 \\
\hline Central North Sea warm-water copepods & 0.217 & -1.500 & 1.011 \\
Central North Sea cold-water copepods & 0.681 & 0.900 & -0.209 \\
Southern North Sea warm-water copepods & 0.506 & -1.407 & 0.947 \\
Southern North Sea cold-water copepods & 0.652 & 0.545 & -0.212 \\
English Channel warm-water copepods & -0.086 & -1.203 & 0.796 \\
English Channel cold-water copepods & 0.669 & -0.380 & 0.226 \\
Central North Sea total copepods & -1.858 & -0.281 & -0.170 \\
Southern North Sea total copepods & -1.845 & -0.278 & -0.304 \\
English Channel total copepods & -1.786 & 0.025 & -0.190 \\
Central North Sea PCI & -1.424 & -0.227 & 0.897 \\
Southern North Sea PCI & -1.613 & 0.030 & 0.728 \\
English Channel PCI & -1.574 & 0.453 & 0.172 \\
Central North Sea diatoms & -0.708 & 0.950 & 1.360 \\
Southern North Sea diatoms & -0.738 & 1.134 & 1.210 \\
English Channel diatoms & -1.220 & 0.883 & 0.093 \\
Central North Sea dinoflagellates & -1.468 & -0.762 & -0.727 \\
Southern North Sea dinoflagellates & -1.182 & -0.714 & -0.921 \\
English Channel dinoflagellates & -1.059 & -0.275 & -0.775 \\
\hline
\end{tabular}
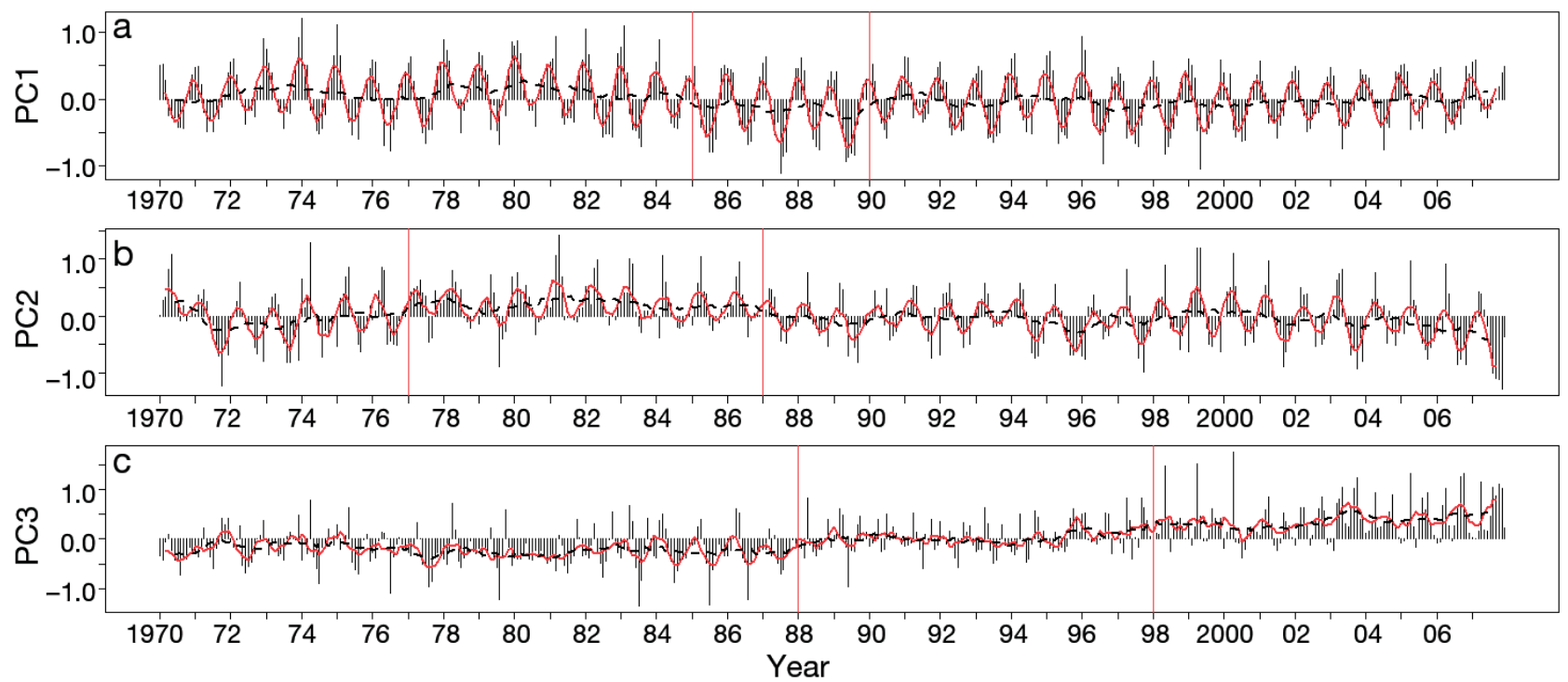

Fig. 3. Representation of the 3 principal components (a: PC1, b: PC2, and c: PC3) of the principal component analysis that included all plankton data. Vertical red lines represent detected shifts. Two trend lines were added to the data: a 6-mo running mean representing the seasonal trend (solid red line) and a 12-mo running mean representing long-term patterns (dashed black line) 
cluding a seasonal as well as a long-term signal, of the community composition of both phyto- and zooplankton in the 3 areas.

The third PC (PC3; 10.5\% explained variance; Fig. 3c, Table 2) represents a different signal, with no apparent seasonal signal. It was highly related to community composition of both phyto- and zooplankton, and to phytoplankton abundance, particularly in areas C1\&2 (central North Sea) and D1\&2 (southern North Sea).

\section{Regime change analyses}

Three types of regime change analysis were applied to the PCs, which together represent $52 \%$ of the variation in the data set (Fig. 3).

All analyses found a regime change in PC1 around 1985 (Table 3). This change was better detected by the methods equipped to deal with seasonal variation. The period pre-1985 was characterised by a strong signal during winter months (positive values) and a weaker signal during summer months (negative values). The period 1985 to 1990 started with a strong signal during the summer months and weaker during the winter months (Fig. 3a). As all the highly related variables to this PC have a negative sign (Table 2), the previous structure would translate as a period pre-1985 in which winter periods were characterised by very low abundances of both phyto- and zooplankton, followed by a second period from 1985 to 1990 where winter abundances were not as low and summer abundances were considerably higher. During the last period, post-1990, the seasonal oscillation is smaller, which is more apparent towards the end of the time series (Fig. 3a).

Table 3. Regime limits found by the different methods. SMW: split-moving window boundary analysis; $\mathrm{CPD}$ : change point detection method; CC: chronological clustering; PC: principal component. Numbers in brackets represent $95 \%$ confidence intervals, which were only available for CPD

\begin{tabular}{|lccc|}
\hline \multirow{2}{*}{ Method } & PC1 & PC2 & PC3 \\
\hline SMW & $1984-85$ & $1977-78$ & $1987-88-89-90$ \\
& 1990 & 1987 & $1998-99$ \\
CPD & 1983 & 1977 & 1988 \\
& $(1976-1990)$ & $(1975-1981)$ & $(1986-1990)$ \\
& & 1987 & 1997 \\
CC & 1985 & $(1985-1989)$ & $(1996-1998)$ \\
& 1990 & 1974 & 1988 \\
& & 1987 & 1998 \\
\hline
\end{tabular}

The different methods agree in the presence of 2 regime changes in PC2 around the years 1978 and 1987 (Fig. 3b, Table 3). These changes were more apparent in the long-term annual signal than in the seasonal signal. This PC showed a clear positive period from 1977 to 1988. Before and after that period, the PC oscillates around zero in a seasonal fashion, although the PC seems to approach a negative period post-2004 (Fig. 3b). This last period was only detected by chronological clustering (Table 3). This PC seems to be related to temperature changes, as warm- and cold-water copepods have an opposite loading sign (Table 2). Thus in the period 1976 to 1987, warm-water copepods would have lower abundances while cold-water copepods would be more abundant. After 1988, the opposite is occurring.

Three different regimes were detected in PC3 (Fig. 3c, Table 3): a negative period until 1988, a period of oscillation around zero from 1988 to 1998, and a third period from 1998 to 2007 characterised by positive values and an upward trend. Variable loadings for this PC are positive for all variables with absolute loading values over 0.7 , except dinoflagellate abundance (Table 2). Therefore, PC3 expressed in terms of actual plankton variables represents an increase in warm-water copepod assemblages unrelated to any significant change in cold-water copepod assemblages; it also reflects an increase in phytoplankton biomass, as represented by PCI, a positive trend in the abundance of diatoms, plus a negative trend in dinoflagellate abundance.

The 95\% confidence intervals resulting from the CPD method (Table 3) became smaller when there was no seasonal pattern in the time series. So, although this method is able to deal with seasonal time series, the accuracy of detection, as shown by the $95 \%$ confidence intervals, is higher with non-seasonal patterns.

PC1 and PC2 were subjected to seasonal decomposition in order to verify the shift in seasonal patterns suggested by the analyses (see Supplement 3 including Fig. S3 at www.int-res.com/articles/suppl/m462 p021_supp.pdf).

\section{Plankton changes}

Post-1977. The years following 1977 had a lower phytoplankton biomass (PCI), and the growing season seemed to be shortened. Both diatoms and dinoflagellates also showed a period of lower total numbers. There was a prominent decrease in total numbers of copepods, and the number of individuals 
belonging to cold-water copepod assemblages increased, while the warm-water copepod assemblages decreased (Fig. 2b,e,f).

Post-1988. After 1988 there was a clear increase in phytoplankton biomass and there seemed to be a decrease in dinoflagellates from 1990 compared to the second half of the 1980s (Fig. 2d). There was a clear decrease in the annual maxima of total number of copepods (Fig. 2b) and an increase in the number of individuals of warm-water copepod assemblages (Fig. 2f). The number of neritic copepods (Assemblage A4 in Table 1) seemed to decrease from the previous years, but they were higher than the years immediately post-1977 (Fig. 2g).

Post-1998. PCI decreased post-1998, particularly in autumn and winter (Fig. 2a, see also Fig. 9b). The main change in the phytoplankton community is the pronounced decrease in dinoflagellates post-1999 (Fig. 2d) and the increase of the diatoms annual maxima (Fig. 2c).

After 1999 there was a further increase in the ratio of warm-water copepod species (data not shown), but this increase in the dominance of warm-water species was not particularly related to an increase in the number of individuals in this assemblage (Fig. 2f) but with a decrease in neritic copepods (Fig. 2g).

Counts of neritic copepods showed a high correlation $(R=0.57)$ with the number of dinoflagellates per sample (Fig. 4). In that period, $38.7 \%$ of the variation of neritic copepods was explained by a GAM using the mean counts of dinoflagellates. Including the
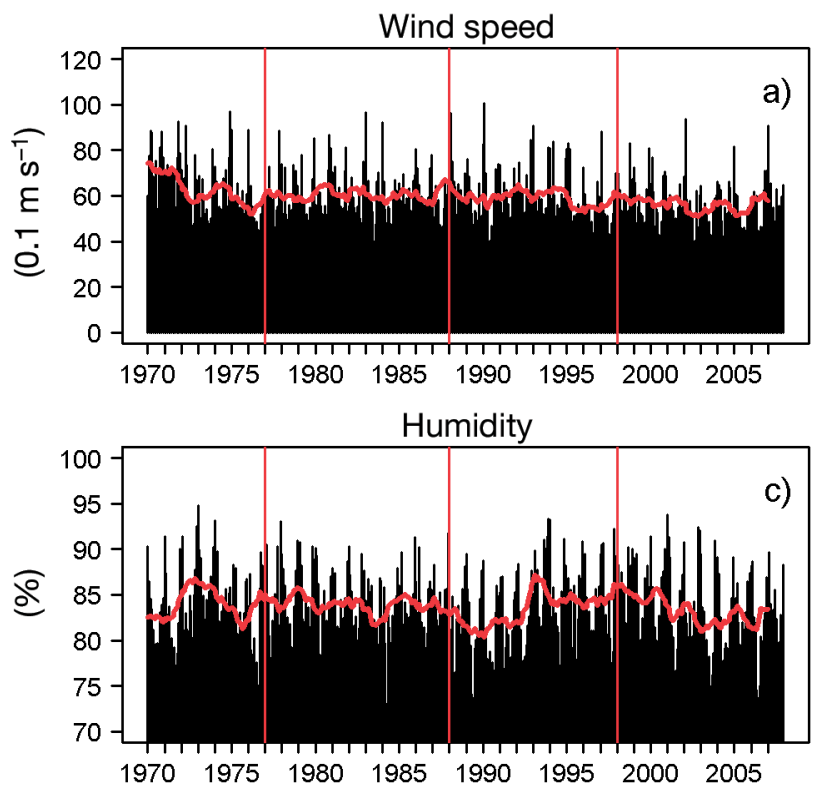

Fig. 5. Trends of environmental drivers: (a) wind speed, (b) temperature, (c) humidity and (d) Atlantic water inflow. Red lines are a 12-mo running mean and represent the annual trend. Regime limits are indicated by vertical red lines mean counts of diatoms as a covariate only added another $0.6 \%$ of explained variation. The GAM showed a linear phase below 100000 dinoflagellates sample $^{-1}$ and a stabilised phase above that number.

\section{Environmental drivers}

The best fit of models explaining the different PCs based on environmental drivers (Fig. 5) were those without a lag period between explanatory and response variables.

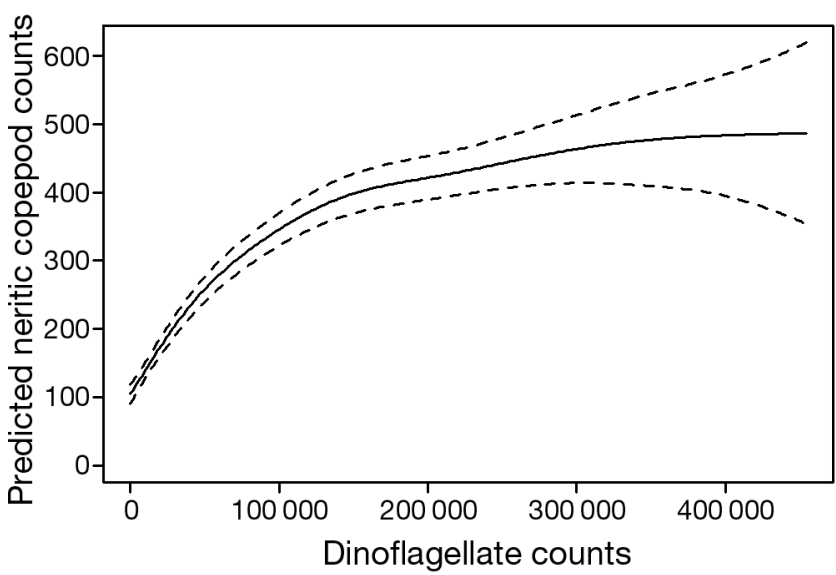

Fig. 4. Predicted neritic copepod counts (mean no. of ind. per sample) as a smooth function of dinoflagellate counts. Dashed lines represent the approximate $95 \%$ confidence limits of the prediction
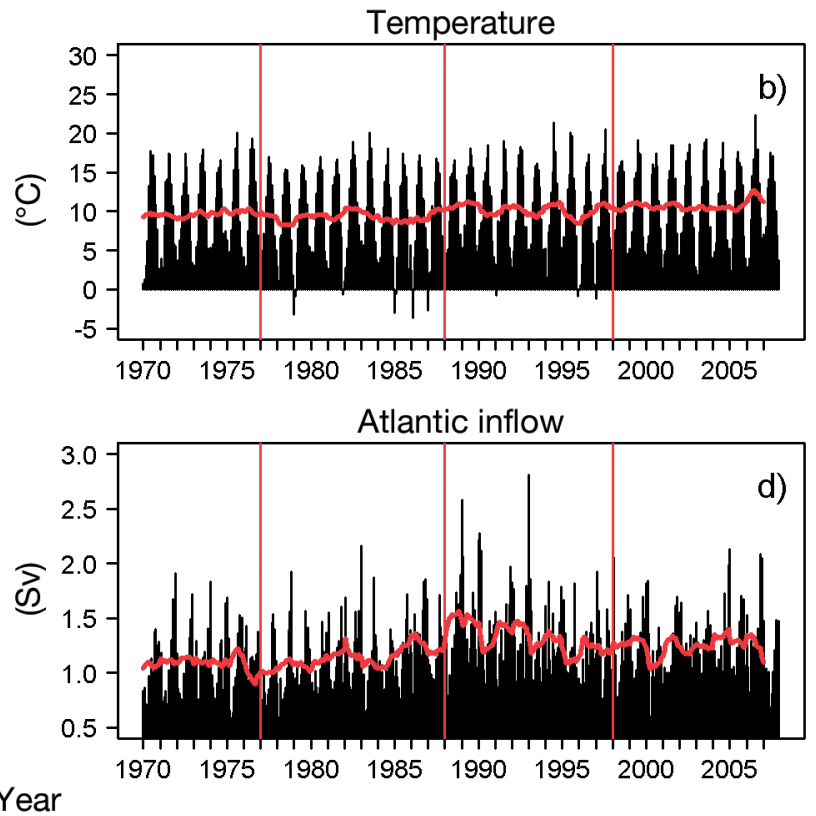
PC1. The pattern represented in the first PC showed high correlation $(>0.5)$ with 6 environmental variables: wind speed, air temperature, solar radiation and humidity at De Kooy Station, and SST in areas $\mathrm{C} 1 \& 2$ and $\mathrm{D} 1 \& 2$.

SST in area D1\&2 and solar radiation at De Kooy were not included in the GAM because of their high collinearity (>0.8) with SST in area C1\&2 and temperature, respectively. Variables that were collinear between 0.5 and 0.8 were included and evaluated during the model selection phase.

Autocorrelation in the model was accounted for using an $\operatorname{ARMA}_{(2,2)}$ autocorrelation structure, which showed the best fit (Table 4).

The best model (Table 4) included wind speed, temperature and humidity at De Kooy (Figs. 5 \& 6). The residuals of this model were then compared with the remaining environmental variables to check for any missing covariate. A relationship with the Atlantic water inflow through the section NorwayOrkneys was found. Refitting the model with this variable as a linear covariate gave a significant improvement in the model AIC (Table 4).

$P C 2$. The second PC only showed correlation values $>0.5$ with environmental variables related to temperature. The highest correlation value was with SST in area C1\&2, so this variable was used as a smoother in a GAM. Temporal autocorrelation in the model residuals was accounted for via an $\mathrm{ARMA}_{(1,3)}$ structure and the best model included water temperature in area C1\&2 with a lag of 1 mo (Fig. 6d).

$P C 3$. The third PC only showed correlation values $<0.5$ with the environmental variables considered in this analysis. The only variables with values $>0.25$ were total nitrogen and ammonia in the central North Sea, and ammonia, total nitrogen and total phosphorus in the southern North Sea. Unfortunately, the nutrient data are not consistent in time, so only values after 1988 were available (Fig. 7). Therefore only 159 data points were used for this model, as opposed to the previous 2 models, which were based on 455 and 456 data points, respectively; thus the results (Fig. 6e) should not be compared with the previous models (Fig. 6a-d).

Yearly variables. The analyses of NAOi and NHTa showed regime limits (CPD method) that coincided with the ones found in the PCs, with the exception of the late 1970s shift that was missing in the NAOi (Fig. 8a, Table 5), although 2 very low NAOi years occurred in 1977 and 1979. After a highly positive phase

Table 4. Model selection for the general additive model of the first principal component. The model with the lowest, or most negative, Akaike information criterion (AIC) is considered the best (bold). Adjusted $\mathrm{R}^{2}$, representing the fit of each model weighed by number of cases, is also included. SST: sea surface temperature

\begin{tabular}{|lrr|}
\hline Smoothing functions & $\mathrm{R}^{2}$ adj. & \multicolumn{1}{c|}{ AIC } \\
\hline Wind speed, temperature, & 0.755 & -169.20 \\
$\quad$ humidity, SST & & \\
Temperature, humidity, SST & 0.738 & -142.77 \\
Wind speed, humidity, SST & 0.613 & -15.49 \\
Wind speed, temperature, SST & 0.724 & -149.78 \\
Wind speed, temperature, humidity & 0.751 & -206.22 \\
Wind speed, temperature, humidity, & & $\mathbf{- 2 3 4 . 9 1}$ \\
$\quad$ Atlantic water inflow & & \\
\hline
\end{tabular}
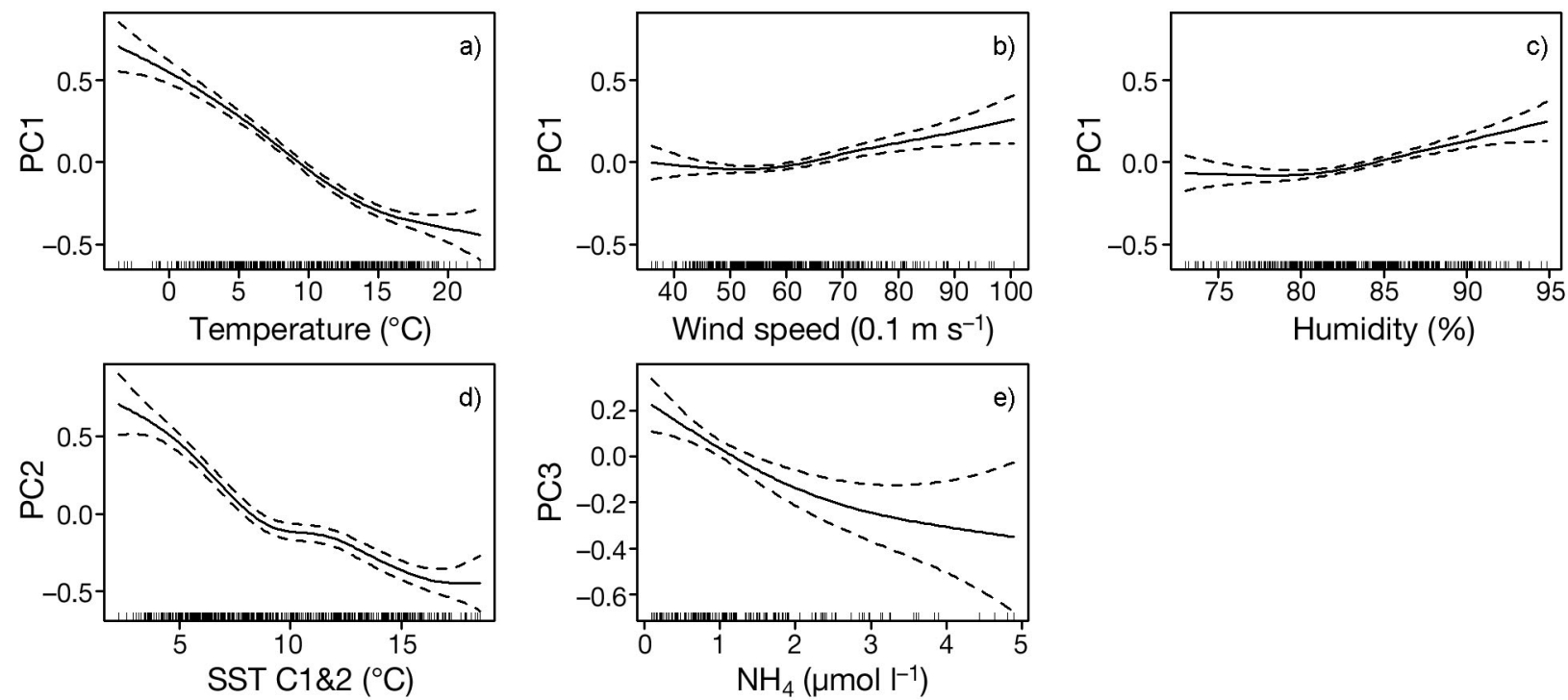

Fig. 6. Smoothing functions of generalised additive models predicting principal components (PCs). PC1 with (a) temperature, (b) wind speed, and (c) humidity; PC2 with (d) sea surface temperature (SST) in area C1\&2; and PC3 with (e) ammonium concentration 

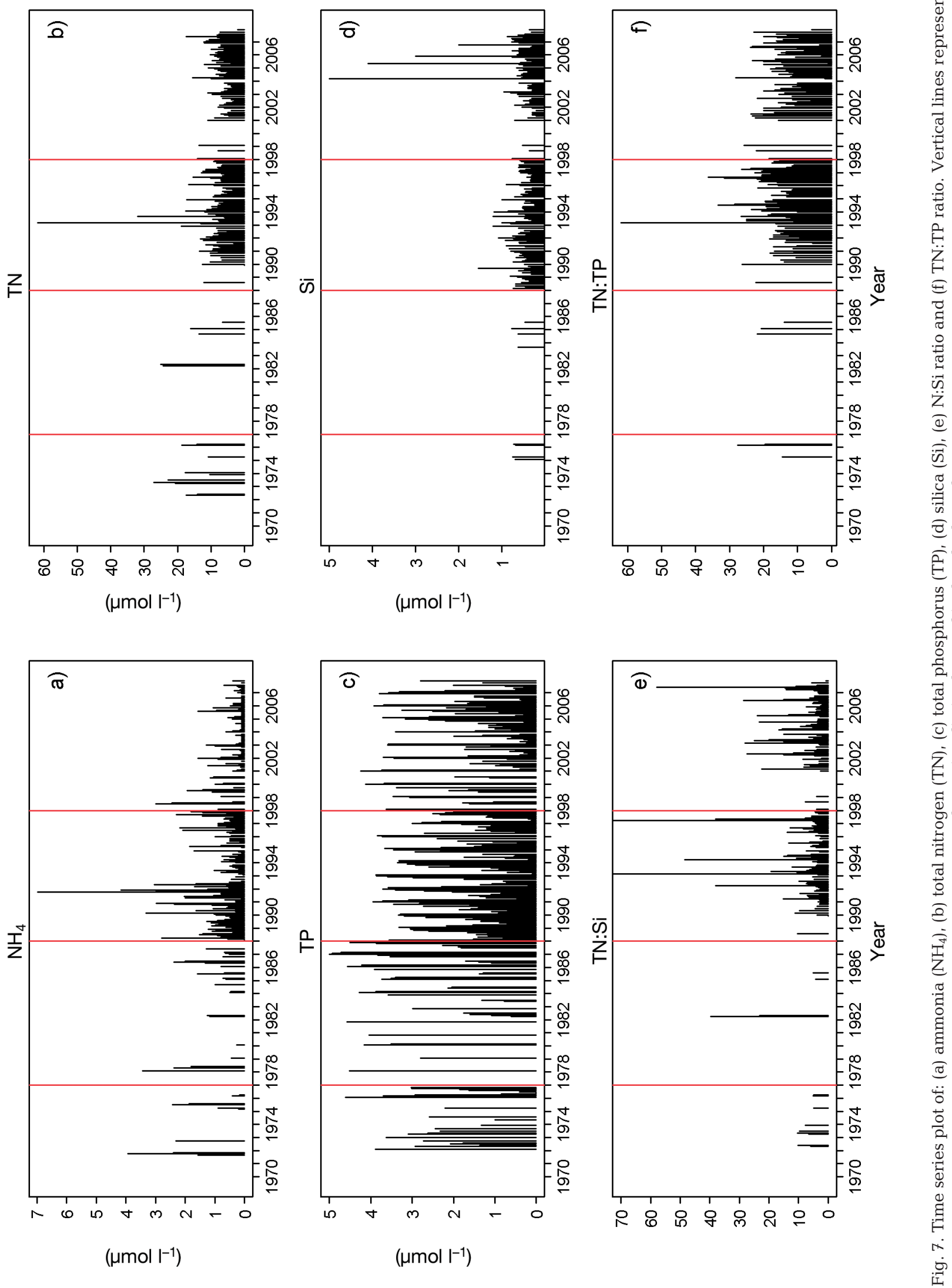


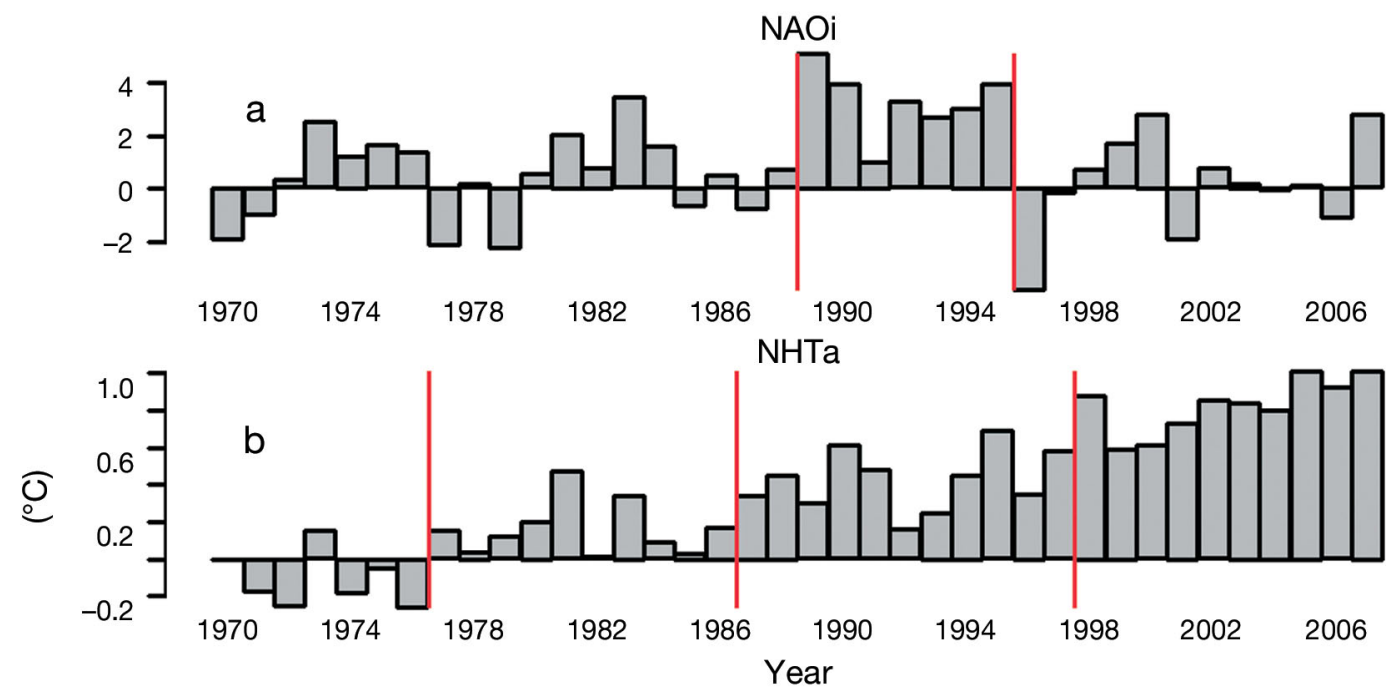

Fig. 8. (a) North Atlantic Oscillation winter index (NAOi) and (b) northern hemisphere surface temperature anomaly $\left(\mathrm{NHTa},{ }^{\circ} \mathrm{C}\right)$. Vertical lines represent regime changes in these time series

Table 5. Regime limits found by the change point detection method for the North Atlantic Oscillation winter index (NAOi) and the northern hemisphere temperature anomaly (NHTa)

\begin{tabular}{lccc}
\hline Indices & \multicolumn{2}{c}{ Regime limits $(95 \%$ confidence intervals $)$} \\
\hline NAOi & & 1988 & 1995 \\
& & $(1986-1992)$ & $(1991-1997)$ \\
NHTa & 1976 & 1986 & 1997 \\
& $(1973-1979)$ & $(1982-1989)$ & $(1995-1999)$ \\
\hline
\end{tabular}

from the second half of the 1980s to the mid-1990s, the NAOi reached a neutral stage (Fig. 8a). Post-1997, NHTa showed several consecutive years with higher values, after a general positive phase with relatively lower values during the period 1977 to 1997 (Fig. 8b).

\section{DISCUSSION}

The results presented here suggest 3 regime changes in the North Sea plankton system around the year 1977 (PC2; Fig. 3), 1988 (PC2 and PC3; Fig. 3) and 1998 (PC3; Fig. 3), propagating from phytoplankton to zooplankton via food-limitation mechanisms. Another 2 changes were found in PC1 in 1985 and 1990 (Fig. 3, Table 3), which we interpret as a period of instability in seasonal patterns after the late 1970s cold episodic event previously identified (Beaugrand 2004b, Beaugrand et al. 2008). Wind speed, air temperature, humidity and Atlantic water inflow were identified as potential environmental drivers of the plankton seasonal dynamics (PC1) in the study area (Table 3).
Neither the PCA (see Supplement 2) nor the inspection of individual variables indicated big differences between the 3 regions. This suggests that our results and discussion are applicable to the whole study area.

\section{Temporal changes and regime shifts}

\section{Post-1977}

This regime change corresponds to the cold episodic event described previously (Reid \& Edwards 2001, Edwards et al. 2002): phytoplankton biomass patterns clearly changed, the spring bloom was less apparent, and there was a higher biomass during the second part of the year (Fig. 9a). This period ended around 1984 (regime change detected in PC1), and gave way to a transition period during the late 1980s. Both the cold-water copepods and PCI returned to previous values during the mid-1980s (Fig. 2), which indicates the episodic character of this regime. Only the warm-water copepods seemed to stay in the cold event configuration throughout the 1980s (Fig. 2).

\section{Post-1988}

The late 1980s North Sea plankton regime shift was also clearly detected in PC2 and PC3, together representing a seasonal and a non-seasonal pattern in the phyto- and zooplankton community composition (Fig. 3, Table 2). There was a clear change from a cold-water copepod-dominated phase (dashed line 

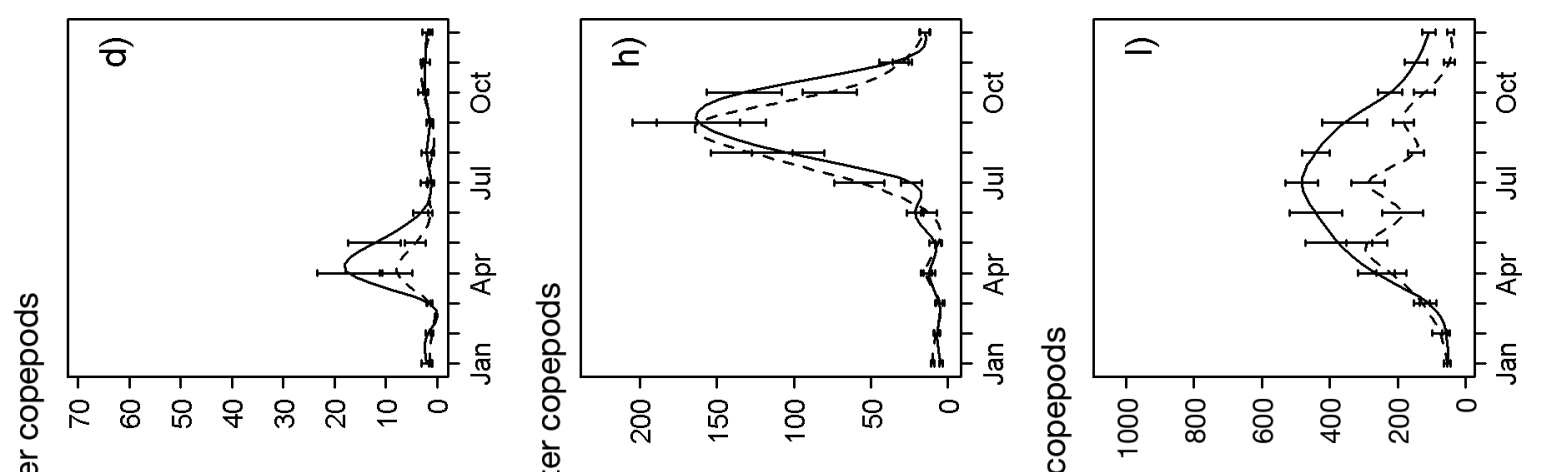

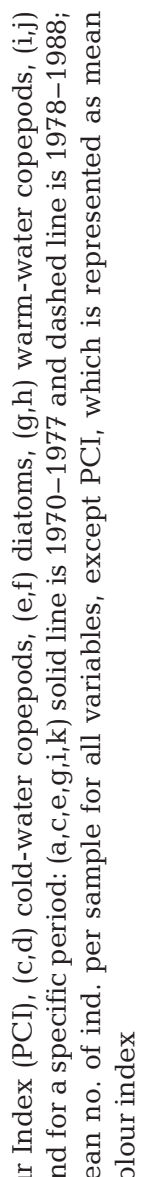
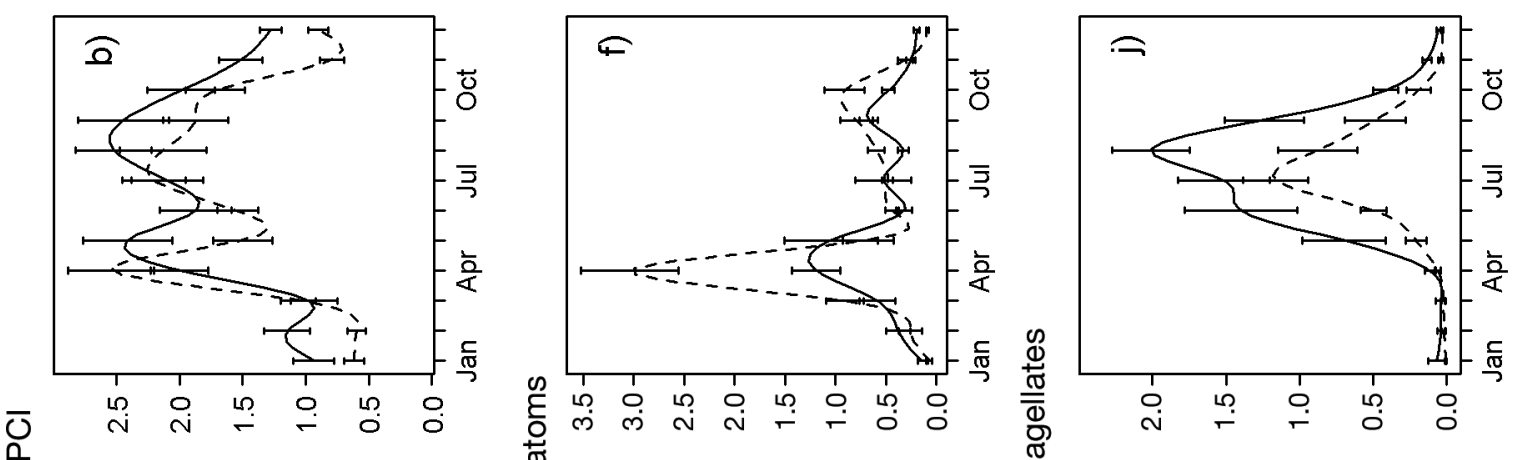

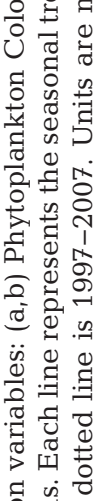
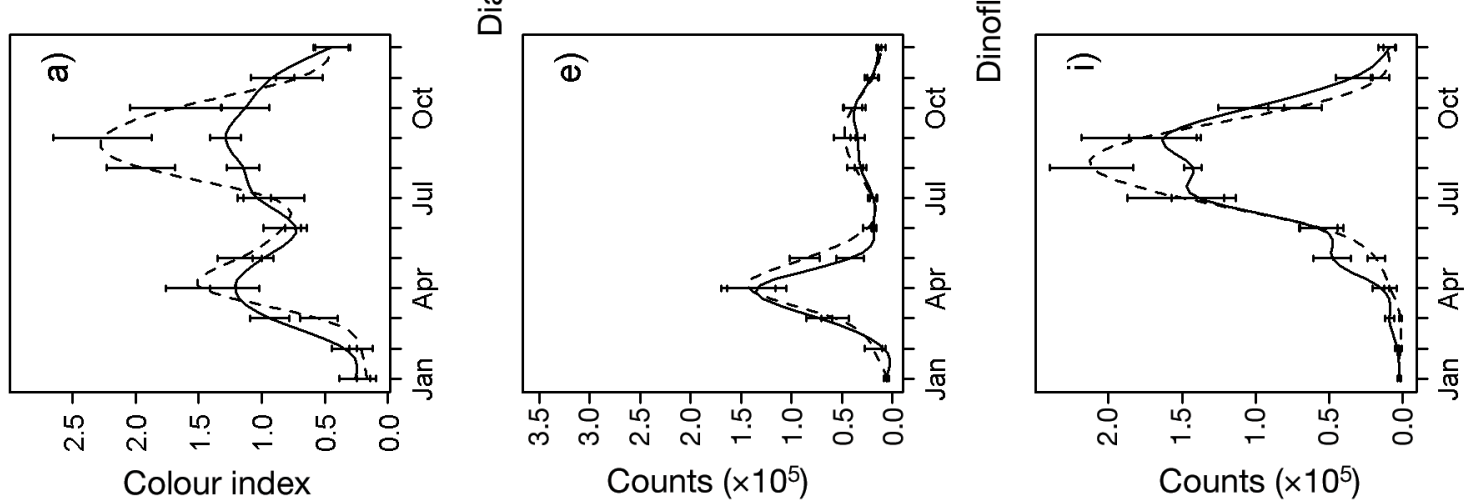

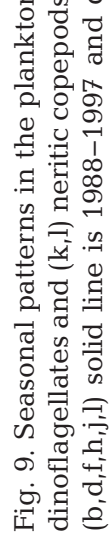


in Fig. 9g,i) to a warm-type plankton system with higher phytoplankton biomass throughout the year (Fig. 9b,h,j).

\section{Post-1998}

A third regime change was detected at the end of the 1990s. After 1998 the relative contribution of warm-water copepod species increased considerably and the total number of copepods decreased (Fig. 2b).

Although the mean numbers of warm-water copepods per sample did not show a significant increase from the previous period (Fig. 9j), the copepod community showed a decrease in neritic species (Fig. 2g). This assemblage dominated in numbers per sample until 1998. After 1998 the neritic copepods contributed only half of the total copepods of the analysed assemblages from August onwards (Fig. 91), when the warm-water copepods started growing in numbers (Fig. 9j). This drop in numbers of neritic copepods can be related to a decrease during the same period in dinoflagellates, a major food source for some of these copepods (Gentsch et al. 2009). Different studies have highlighted the importance of a high and constant food supply for the success of some neritic copepod species (Vidal 1980, Evans 1981, Tsuda 1994, Gentsch et al. 2009), so a decrease in prey, e.g. dinoflagellates, during part of the year could lead to limitation of population growth.

Although the number of diatoms showed an increase post-1998, particularly during the spring bloom (Fig. 9d), dinoflagellates showed an important decrease (Fig. 9f). The linear increase in neritic copepods shown by the GAM below 100000 dinoflagellates sample $\mathrm{s}^{-1}$ and the stable phase above that number (Fig. 4) may indicate food limitation.

Moreover, Vidal (1980) showed how critical food concentration increased with increasing temperature for both growth and development of the most numerous copepod species, Pseudocalanus. This situation would also apply to the present study, as temperature was higher post-1998 (Fig. 5a).

\section{Environmental drivers}

\section{PC1}

Wind speed and temperature were the main abiotic variables driving plankton biomass seasonal dynamics in the North Sea during this period (Table 4). Wind speed and temperature at De Kooy decreased and increased respectively after 1998, even though 1988 was the largest shift in temperature (Fig. 5a) and 1996 the sharpest decrease in wind speed (Fig. 5b). This was not the case for the Atlantic water inflow through the Orkneys-Norway transect (Fig. 5d), which showed a large decrease post-1996 after a period of high inflow in the early 1990s.

All of these variables are related to water mixing dynamics. In the 1998 case, lower wind speeds and higher temperatures would have led to a stronger and more permanent stratification.

\section{$\mathrm{PC} 2$}

There is a clear relationship between PC2 and temperature. This PC represents clearly the late 1970s cold episodic event and the late 1980s regime shift, which had a clear link with SST changes (Edwards et al. 2002, Beaugrand \& Reid 2003).

The North Atlantic inflow to the North Sea has been previously linked to NAOi (Reid et al. 2003), while stratification patterns have additionally been linked with NHTa (Beaugrand 2004b).

Our analyses of these 2 indices agree with previous findings (Beaugrand 2004b), and point to the relationship between these indices and the ecosystem changes in the North Sea.

PC3

Because of the limited time coverage of the nutrient data, only relationships with the 1998 shift can be discussed. The decrease in dinoflagellates post-1998 might possibly be related to a change in nutrient balance in the North Sea post-1998 (Fig. 10). In this period, nitrogen values were considerably reduced (Fig. 10b), and consequently the total nitrogen:total phosphorus ratio dropped below 20, which would indicate nitrogen limitation (Guildford \& Hecky 2000) (our Fig. 10g). The most apparent change in dissolved nitrogen compounds was found in ammonia (Fig. 10a), which consistently showed lower mean values post-1998, although nitrate also showed lower levels after the spring bloom (Fig. 10e). In contrast, silica only showed a consistently significant decrease during the autumn period in the post-1998 period (Fig. 10d). The decrease in nitrogen could be the result of both the decrease in influx of nutrient-rich North Atlantic waters and a strong and more stable stratification that could promote the locking up of inorganic nutrients below the photic zone (Brock- 

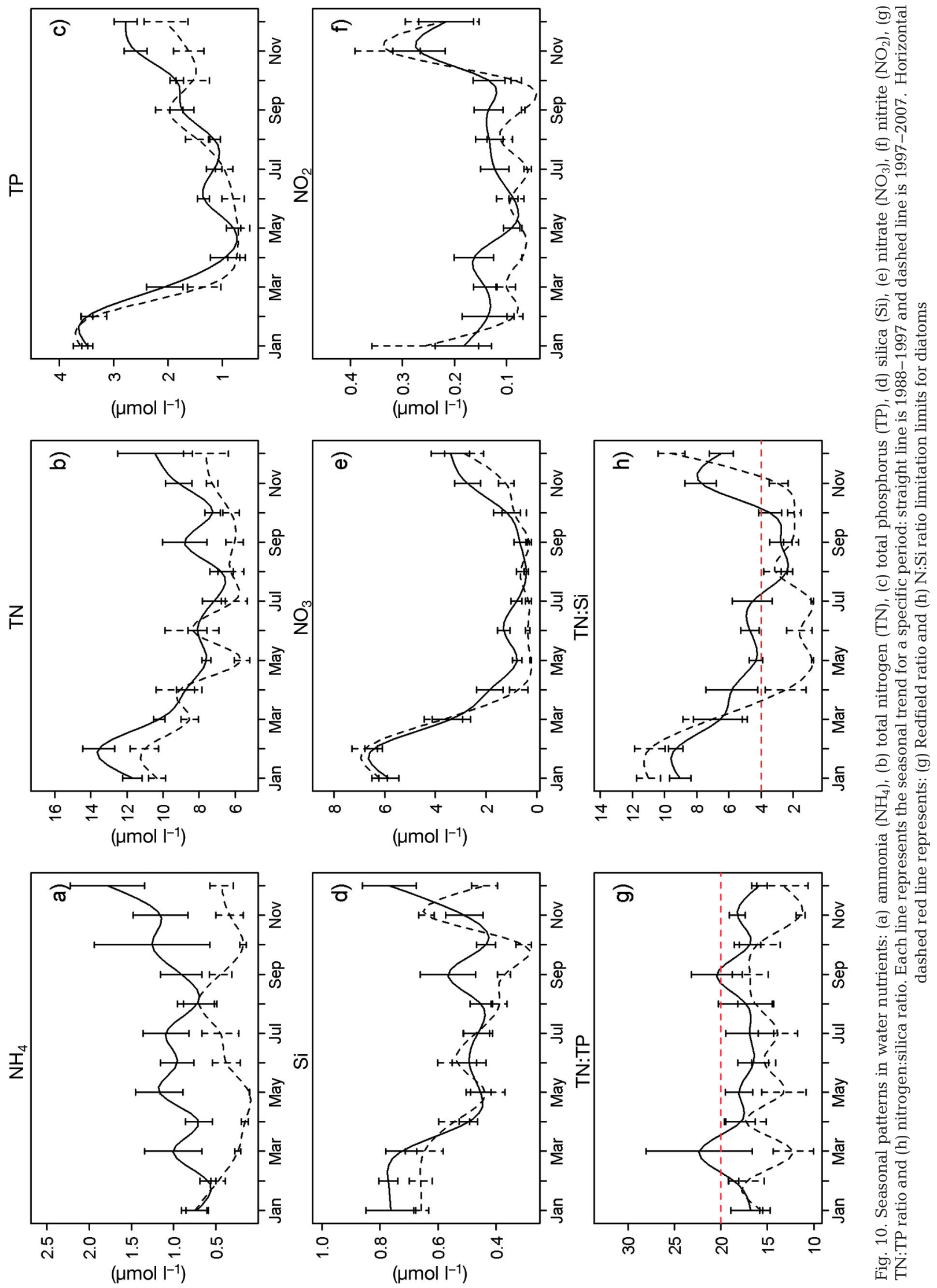
mann et al. 1990), and a subsequent shift in the nitrogen and phosphorus cycles. McQuatters-Gollop et al. $(2007,2009)$ suggested that nitrogen may be limiting in the open North Sea, and they discussed how, compared to coastal North Sea areas, changes in nutrient state are slower in open waters and less influenced by anthropogenic impacts.

In this new nitrogen-limited scenario, diatoms did not show any decrease in the second half of the year relative to the pre-1998 scenario because they would still be silica-limited, not nitrogen-limited as shown by the nitrogen:silica ratios, which were still around 4:1 during the late growing season, i.e. August and September (Fig. 10h). For diatoms, nitrogen:silica ratios of 4:1 have been shown to be an indication of silica limitation, not nitrogen limitation (Gilpin et al. 2004).

In contrast, dinoflagellates showed a clear drop in abundance (Fig. 9f). This could be explained by phytoplankton becoming dominated by smaller species and bacteria because of their higher competitive ability for limiting factors (Riegman et al. 1993). In this case there would not be enough nitrogen in the system to sustain the high dinoflagellate abundances recorded pre-1998.

\section{Further implications}

The changes in plankton community structure presented in this paper may have knock-on effects on higher trophic levels. The copepod species that form the neritic assemblage (i.e. Pseudocalanus and Paracalanus spp., Temora longicornis) are the main prey items for larvae of several important fish species in the North Sea, such as herring and sprat (Last 1989, Arrhenius 1996) and cod and whiting (Shaw et al. 2008). A significant drop in prey abundances (i.e. neritic copepods), caused by the decrease in dinoflagellate numbers, could potentially lead to more competition for prey, less larval survival and therefore lower recruitment for these species. For herring this has already been shown (Payne et al. 2009). The timing of the North Sea herring recruitment failure in the year 2000 (Payne et al. 2009) coincides with the shift detected in plankton community structure in 1998. Furthermore, a preliminary analysis of recruitment data in the period 1990 to 2008 for 5 North Sea fish species (cod Gadus morhua, whiting Merlangius merlangus, herring Clupea harengus, sandeel Ammodytes spp. and haddock Melanogrammus aeglefinus) showed a shift between 2000 and 2002 (95\% confidence interval; Fig. 11). Recruitment values for these species for the 2000s are lower than in the previous period, although further analyses are required to weigh the exact relationship with larval prey (plankton) availability for each species and the reason behind different timings of recruitment failure for different species.

This fish recruitment failure could propagate to higher trophic levels. The sandeel recruitment collapse has already been related to seabird breeding
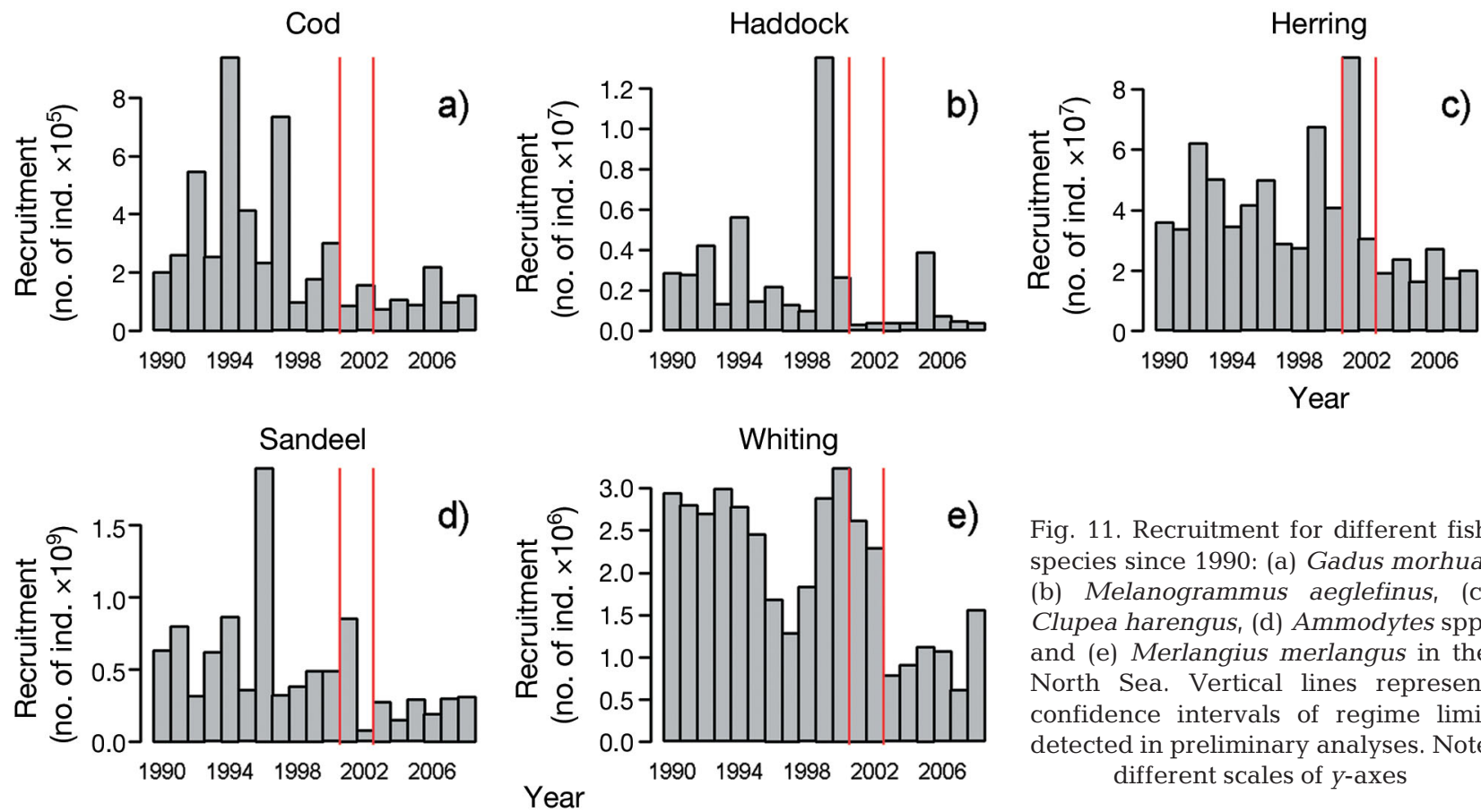

Fig. 11. Recruitment for different fish species since 1990: (a) Gadus morhua, (b) Melanogrammus aeglefinus, (c) Clupea harengus, (d) Ammodytes spp. and (e) Merlangius merlangus in the North Sea. Vertical lines represent confidence intervals of regime limit detected in preliminary analyses. Note different scales of $y$-axes 
failure on the North Sea coast (Proffitt 2004, Wanless et al. 2005). This propagation in time through different trophic levels would support the idea of a new regime shift in the late 1990s.

Further research is needed to assess the propagation of this shift and also the implication of changes in the nutrient balance for the plankton community and the different reactions of nitrogen, phosphorus and silica cycles to the environmental changes.

Although the results of our analyses seem to have a valid ecological interpretation, several considerations should be taken into account when working with CPR data: (1) the semi-quantitative nature of the PCI might make interpretation of total phytoplankton difficult; (2) the grouping of dinoflagellates and diatoms hampers the interpretation of food availability to the zooplankton community, i.e. a decrease in dinoflagellates could not be detrimental if it is caused by certain species that are not edible by the existing zooplankton, either because of their size or any other factors; and (3) diatoms and dinoflagellates, which are counted in CPR samples, are not the only major phytoplankton functional groups. For the sake of discussion, we assumed here that the temporal patterns we found both in dinoflagellates and diatoms, although strictly being size classes collected in a $270 \mu \mathrm{m}$ mesh, are a good representation of slightly smaller size classes.

Acknowledgements. We thank the Sir Allister Hardy Foundation for Ocean Science for allowing the establishment and maintenance of the CPR data set, in particular David Johns, who kindly addressed all the requests for data used in these analyses. We also thank 4 anonymous reviewers for their comments on structure and content of the manuscript and Amanda Lloyd for improving the English and useful comments. We are grateful to all the data providers who made these analyses possible: Morten Skogen from the Institute of Marine Research in Norway for the data on Atlantic water inflow in the North Sea, ICES and the Rijkswaterstaat for environmental and oceanographic data, the Met Office (www.metoffice.gov.uk/hadobs) for the temperature anomaly data, and all the monitoring programmes that allow the creation of long-term data sets. This research was supported by the Building with Nature research programme (BwN).

\section{LITERATURE CITED}

- Alheit J, Mollmann C, Dutz J, Kornilovs G, Loewe P, Mohrholz V, Wasmund N (2005) Synchronous ecological regime shifts in the central Baltic and the North Sea in the late 1980s. ICES J Mar Sci 62:1205-1215

> Andersen T, Carstensen J, Hernandez-Garcia E, Duarte CM (2009) Ecological thresholds and regime shifts: approaches to identification. Trends Ecol Evol 24:49-57

> Arrhenius F (1996) Diet composition and food selectivity of 0-group herring (Clupea harengus L.) and sprat (Sprat- tus sprattus (L.)) in the northern Baltic Sea. ICES J Mar Sci 53:701-712

Batten SD, Walne AW, Edwards M, Groom SB (2003) Phytoplankton biomass from continuous plankton recorder data: an assessment of the phytoplankton colour index. $\mathrm{J}$ Plankton Res 25:697-702

Beaugrand G (2003) Long-term changes in copepod abundance and diversity in the north-east Atlantic in relation to fluctuations in the hydroclimatic environment. Fish Oceanogr 12:270-283

Beaugrand G (2004a) Monitoring marine plankton ecosystems. I: Description of an ecosystem approach based on plankton indicators. Mar Ecol Prog Ser 269:69-81

- Beaugrand G (2004b) The North Sea regime shift: evidence, causes, mechanisms and consequences. Prog Oceanogr 60:245-262

Beaugrand G, Ibanez F (2004) Monitoring marine plankton ecosystems. II: Long-term changes in North Sea calanoid copepods in relation to hydro-climatic variability. Mar Ecol Prog Ser 284:35-47

Beaugrand G, Reid PC (2003) Long-term changes in phytoplankton, zooplankton and salmon related to climate. Glob Change Biol 9:801-817

Beaugrand G, Ibañez F, Lindley JA, Reid PC (2002) Diversity of calanoid copepods in the North Atlantic and adjacent seas: species associations and biogeography. Mar Ecol Prog Ser 232:179-195

> Beaugrand G, Brander KM, Lindley JA, Souissi S, Reid PC (2003) Plankton effect on cod recruitment in the North Sea. Nature 426:661-664

> Beaugrand G, Edwards M, Brander K, Luczak C, Ibanez F (2008) Causes and projections of abrupt climate-driven ecosystem shifts in the North Atlantic. Ecol Lett 11: 1157-1168

> Becker GA, Pauly M (1996) Sea surface temperature changes in the North Sea and their causes. ICES J Mar Sci 53:887-898

> Brockmann UH, Laane RWPM, Postma J (1990) Cycling of nutrient elements in the North Sea. Neth J Sea Res 26: 239-264

Brohan P, Kennedy JJ, Harris I, Tett SFB, Jones PD (2006) Uncertainty estimates in regional and global observed temperature changes: a new data set from 1850. J Geophys Res Atmos 111:D12106 doi:10.1029/2005JD006548

> Colebrook JM (1979) Continuous Plankton Records: seasonal cycles of phytoplankton and copepods in the North Atlantic ocean and the North Sea. Mar Biol 51:23-32

- Collie JS, Richardson K, Steele JH (2004) Regime shifts: Can ecological theory illuminate the mechanisms? Prog Oceanogr 60:281-302

- Edwards M, Reid PC, Planque B (2001) Long-term and regional variability of phytoplankton biomass in the Northeast Atlantic (1960-1995). ICES J Mar Sci 58:39-49

Edwards M, Beaugrand G, Reid PC, Rowden AA, Jones MB (2002) Ocean climate anomalies and the ecology of the North Sea. Mar Ecol Prog Ser 239:1-10

Evans F (1981) An investigation into the relationship of sea temperature and food supply to the size of the planktonic copepod Temora longicornis Müller in the North Sea. Estuar Coast Shelf Sci 13:145-158

> Gentsch E, Kreibich T, Hagen W, Niehoff B (2009) Dietary shifts in the copepod Temora longicornis during spring: evidence from stable isotope signatures, fatty acid biomarkers and feeding experiments. J Plankton Res 31: 45-60 
Gilpin LC, Davidson K, Roberts E (2004) The influence of changes in nitrogen: silicon ratios on diatom growth dynamics. J Sea Res 51:21-35

Gordon AD, Birks HJB (1972) Numerical methods in quaternary paleoecology. 1. Zonation of pollen diagrams. New Phytol 71:961-979

Guildford SJ, Hecky RE (2000) Total nitrogen, total phosphorus, and nutrient limitation in lakes and oceans: Is there a common relationship? Limnol Oceanogr 45: 1213-1223

Hare SR, Mantua NJ (2000) Empirical evidence for North Pacific regime shifts in 1977 and 1989. Prog Oceanogr 47: 103-145

Hurrell JW, Deser C (2009) North Atlantic climate variability: the role of the North Atlantic Oscillation. J Mar Syst 78:28-41

Juggins S (2009) rioja: analysis of quaternary science data [R package]. R Foundation for Statistical Computing, Vienna. http://cran.r-project.org/

> Kirby RR, Beaugrand G (2009) Trophic amplification of climate warming. Proc R Soc B Biol Sci 276:4095-4103

- Kirby RR, Beaugrand G, Lindley JA, Richardson AJ, Edwards M, Reid PC (2007) Climate effects and benthicpelagic coupling in the North Sea. Mar Ecol Prog Ser 330:31-38

Kirby RR, Beaugrand G, Lindley JA (2008) Climate-induced effects on the meroplankton and the benthic-pelagic ecology of the North Sea. Limnol Oceanogr 53:1805-1815

Last JM (1989) The food of herring, Clupea harengus, in the North Sea, 1983-1986. J Fish Biol 34:489-501

Legendre P, Legendre L (1998) Chapter 9: Ordination in reduced space. In: Developments in environmental modelling, Vol 20. Elsevier, Amsterdam, p 387-480

McQuatters-Gollop A, Raitsos DE, Edwards M, Pradhan Y, Mee LD, Lavender SJ, Attrill MJ (2007) A long-term chlorophyll data set reveals regime shift in North Sea phytoplankton biomass unconnected to nutrient trends. Limnol Oceanogr 52:635-648

McQuatters-Gollop A, Gilbert AJ, Mee LD, Vermaat JE, Artioli Y, Humborg C, Wulff F (2009) How well do ecosystem indicators communicate the effects of anthropogenic eutrophication? Estuar Coast Shelf Sci 82:583-596

Mielke PW, Berry KJ, Brier GW (1981) Application of multiresponse permutation procedures for examining seasonal changes in monthly mean sea-level pressure patterns. Mon Weather Rev 109:120-126

Oksanen J, Blanchet FG, Kindt R, Legendre P and others (2010) vegan: community ecology package [R package version 2.0-0]. R Foundation for Statistical Computing, Vienna. http://cran.r-project.org/

Payne MR, Hatfield EMC, Dickey-Collas M, Falkenhaug T and others (2009) Recruitment in a changing environment: the 2000s North Sea herring recruitment failure. ICES J Mar Sci 66:272-277

Pinheiro J, Bates D, Debroy S, Sarkar D, R Development Core Team (2009) nlme: linear and nonlinear mixed effects models [R package version 3.1-101]. R Foundation for Statistical Computing, Vienna. http://cran.r-project.org

Proffitt F (2004) Reproductive failure threatens bird colonies on North Sea coast. Science 305:1090

Quandt RE (1958) The estimation of the parameters of a linear-regression system obeying two separate regimes. J Am Stat Assoc 53:873-880

R Development Core Team (2012) R: a language and envi- ronment for statistical computing. R Foundation for Statistical Computing, Vienna. www.r-project.org

> Raitsos DE, Reid PC, Lavender SJ, Edwards M, Richardson AJ (2005) Extending the SeaWiFS chlorophyll data set back 50 years in the northeast Atlantic. Geophys Res Lett 32:L06603 doi:10.1029/2005GL022484

Reid P, Edwards M (2001) Long-term changes in the pelagos, benthos and fisheries of the North Sea. Mar Biodiversity 31:107-115

$>$ Reid PC, Battle EJV, Batten SD, Brander KM (2000) Impacts of fisheries on plankton community structure. ICES J Mar Sci 57:495-502

> Reid PC, Borges MD, Svendsen E (2001a) A regime shift in the North Sea circa 1988 linked to changes in the North Sea horse mackerel fishery. Fish Res 50:163-171

Reid PC, Holliday NP, Smyth TJ (2001b) Pulses in the eastern margin current and warmer water off the north west European shelf linked to North Sea ecosystem changes. Mar Ecol Prog Ser 215:283-287

Reid PC, Edwards M, Beaugrand G, Skogen M, Stevens D (2003) Periodic changes in the zooplankton of the North Sea during the twentieth century linked to oceanic inflow. Fish Oceanogr 12:260-269

Richardson K, Pedersen FB (1998) Estimation of new production in the North Sea: consequences for temporal and spatial variability of phytoplankton. ICES J Mar Sci 55: $574-580$

> Riegman R, Kuipers BR, Noordeloos AAM, Witte HJ (1993) Size-differential control of phytoplankton and the structure of plankton communities. Neth J Sea Res 31:255-265

Shaw M, Diekmann R, Van DerKooij J, Milligan S, Bromley P, Righton D (2008) Assessment of the diets of cod Gadus morhua and whiting Merlangius merlangus juveniles in a frontal region close to the Norwegian Trench: co-existence or competition? J Fish Biol 73:1612-1634

Tsuda A (1994) Starvation tolerance of a planktonic marine copepod Pseudocalanus newmani Frost. J Exp Mar Biol Ecol 181:81-89

Vidal J (1980) Physioecology of zooplankton. II. Effects of phytoplankton concentration, temperature, and body size on the development and molting rates of Calanus pacificus and Pseudocalanus sp. Mar Biol 56:135-146

> Wanless S, Harris MP, Redman P, Speakman JR (2005) Low energy values of fish as a probable cause of a major seabird breeding failure in the North Sea. Mar Ecol Prog Ser 294:1-8

> Warner AJ, Hays GC (1994) Sampling by the continuous plankton recorder survey. Prog Oceanogr 34:237-256

Weijerman M, Lindeboom H, Zuur AF (2005) Regime shifts in marine ecosystems of the North Sea and Wadden Sea. Mar Ecol Prog Ser 298:21-39

Wood SN (2006) Generalized additive models: an introduction with R. Chapman \& Hall/CRC, Boca Raton, FL

Zeileis A, Kleiber C, Kramer W, Hornik K (2003) Testing and dating of structural changes in practice. Comput Stat Data Anal 44:109-123

Zuur AF, Ieno EN, Smith GM (2007) Analysing ecological data. Springer, New York, NY

Zuur AF, Ieno EN, Smith GM, Walker N, Saveliev AA (2009) Mixed effects models and extensions in ecology with R. Springer-Verlag, New York, NY

Zuur AF, Ieno EN, Elphick CS (2010) A protocol for data exploration to avoid common statistical problems. Methods Ecol Evol 1:3-14

Submitted: December 20, 2010; Accepted: May 14, 2012

Proofs received from author(s): August 9, 2012 